\title{
A AgUISIÇÃo DA MEMÓRIA E DA IMAGINAÇÃo NA FILOSOFIA EXPERIMENTAL DE DAVID HUME
}

(The acquisition of memory and imagination in the experimental philosophy of David Hume)

\section{Marcos César Seneda *}

Resumo: Reduzindo a fonte dos conhecimentos aos dados sensíveis, o empirismo pode ser concebido basicamente de dois modos: a partir da aquisição dos conteúdos do pensamento, ou a partir da constituição empírica da própria subjetividade. A segunda hipótese, em suas linhas gerais, foi apresentada explicitamente por G. Deleuze. Este texto, ao examinar esta segunda hipótese, restringe-se a uma análise exaustiva da memória e da imaginação, procurando expor os passos pelos quais Hume constitui distintos modos de operar da mente humana em conformidade com os pressupostos radicais do que denominou filosofia experimental.

Palavras-chave: Ideias, impressões, memória, imaginação, ordem, intensidade.

Abstract: When reducing the source of knowledge to sense data, empiricism can basically be conceived in two ways: either through the acquisition of thought content, or through the empirical constitution of subjectivity itself. The second hypothesis was explicitly presented by G. Deleuze. This paper deals with the second hypothesis and limits

\footnotetext{
* Professor do Programa de Pós-Graduação em Filosofia e Professor Adjunto do Instituto de Filosofia (IFILO) da Universidade Federal de Uberlândia (UFU). Este texto apresenta o resultado parcial de um trabalho realizado com o auxílio da FAPEMIG Fundação de Apoio à Pesquisa do Estado de Minas Gerais. Artigo submetido a avaliação no dia 07/10/2011 e aprovado para publicação no dia 19/03/2012.
} 
itself to an exhaustive analysis of memory and imagination. It seeks to trace the steps by which Hume constituted distinct modes of operation of the human mind, according to the radical presuppositions of what he called experimental philosophy.

Key words: Ideas, impressions, memory, imagination, order, intensity.

C onquanto possa ser constatado um consenso entre os comentadores de que Hume ${ }^{1}$ pretendia tornar-se o Newton das ciências morais ${ }^{2}$, cumpre averiguar, à parte desta consistente analogia, o alcance e a penetração epistêmica desta intenção: se se trata de mera analogia, se se trata de um procedimento aplicável somente aos assuntos morais, se se trata da apropriação de um método que está subjacente à composição de toda a obra $^{3}$. Posto que as duas primeiras hipóteses têm sido bastante exploradas pela bibliografia especializada, dedicar-nos-emos, neste breve ensaio, ao exame da terceira hipótese, mas restringindo o seu alcance. $\mathrm{O}$ objetivo do presente exame, portanto, cingir-se-á ao estudo da memória e da imaginação, a partir do seguinte pressuposto: de que somente a partir da aplicação rigorosa do método experimental podemos conceber a formação destas duas "faculdades", uma vez que D. Hume, para ser consequente com a filosofia que propõe, precisa descrever a gênese empírica da própria subjetividade.

Principiemos pela memória e pela imaginação. Mas já de início uma dificuldade apresenta-se no trajeto do método: a ausência do objeto. $\mathrm{O}$ empirismo é por si um método, no qual os conteúdos empíricos - podemos assim dizer

\footnotetext{
${ }^{1}$ Para tornar mais ágil a menção às obras de D. Hume no corpo do texto, ela será feita mediante uma palavra indicativa, que aqui segue entre parênteses o título respectivo, a saber: Investigação sobre o entendimento humano (Investigação), Resumo de um livro ultimamente publicado, intitulado Tratado da natureza humana (Abstract), Tratado da natureza humana (Tratado). As duas últimas obras, o Abstract e o Tratado, serão citadas a partir da edição preparada por L. A. Selby-Bigge e P. H. Nidditch, sendo a tradução de nossa responsabilidade.

2 J. Noxon (1987, p. 42-43) documenta este traço comum entre os seguintes comentadores: J. Passmore, K. Smith, C. Hendel, V. C. Chappell e A. Flew.

${ }^{3}$ Não é objetivo deste texto, contudo, examinar as correspondências que podem ser traçadas entre as obras de Newton e Hume, seja perguntando-se pelo conhecimento que Hume tinha de Newton, seja avaliando como Hume opera com a construção de hipóteses ou com o procedimento de análise. Quem quiser examinar o problema sob este ângulo poderá consultar, por exemplo, J. Noxon (1987) ou Y. Michaud (1999).
} 
- têm prioridade sobre os conteúdos transcendentais ou psicológicos (G. Deleuze, 2001, p. 95). Mas se formulássemos isso com a radicalidade humiana, diríamos que em momento algum a organização do dado precede ou determina a apresentação do dado. Essa questão, fundamental para a condução do método, é assim exposta por G. Deleuze:

A crítica é empírica quando, colocando-se de um ponto de vista puramente imanente, de onde seja possível, uma descrição que encontra sua regra em hipóteses determináveis e seu modelo na física, se pergunta a propósito do sujeito: como se constitui ele no dado? (2001, p. 95).

G. Deleuze percebe a dificuldade inaudita do método, na medida em que pressupõe não só que os conteúdos têm de ser extraídos empiricamente, mas também que o sujeito deve ser constituído empiricamente. Não se trata de conceber o sujeito como um conjunto ou somatória de conteúdos empíricos, mas de dotá-lo de faculdades que não podem - por pressuposição metodológica - ter existência prévia. E esta dificuldade se acentua pelo compromisso que Hume (omitindo sua identidade), assume com o leitor na introdução do Abstract. "Ele se propõe", afirma sem se subscrever, "a fazer a anatomia da natureza humana de modo regular, e promete não tirar conclusões a não ser onde é autorizado pela experiência (is authorized by experience)" (Hume, 1992, p. 646). Notemos como, num golpe absolutamente moderno, Hume cede a autoridade à experiência, e se compromete a não interpor-se entre ela e o leitor, aceitando avançar somente na medida em que ela lhe forneça solo para sustentar suas asserções. Hume precipita, portanto, uma dificuldade que outros sistemas não enfrentam, porque não parte do confronto entre subjetividade e dado empírico, mas principia pela gênese da própria subjetividade. Nesse sentido, embora utilize vicariamente o termo "faculdade", a memória e a imaginação jamais poderiam ser assim compreendidas, pois não designam esferas potencialmente já constituídas para operarem com conteúdos a serem dados. Pelo contrário, tudo o que operatoriamente designar o lembrar e o imaginar terá de ser adquirido no contato com o dado empírico. Assim, os dados empíricos não são apropriados por modos de operar já potencialmente constituídos para recebê-los, mas são esses modos de operar que hão de se constituir a partir das relações travadas entre os próprios dados empíricos ${ }^{4}$.

\footnotetext{
${ }^{4}$ À primeira vista, essa questão pode parecer simples, porque os dados empíricos podem parecer um índice seguro e dotado de bastante evidência para uma teoria da significação das ideias. Mas a dificuldade surge quando percebemos o fundamento móvel da discussão: quando os intérpretes dizem se reportar à experiência, nem sempre se reportam a um locus que reconhecem como um denominador comum; e isso tem importância direta sobre o modo como é lido o Tratado. No prefácio de seu livro, Annette Baier observa: "Alguém pode dizer que a epistemologia está dada e se encerra no âmbito do Livro Um, que as paixões estão reservadas ao Livro Dois, e que o Livro Três é um apêndice de interesse somente para os filósofos da moral. Ao contrário, Hume diz-nos no começo do Livro Três que sua obra espera adquirir mais força na medida em que
} 
O projeto dessa constituição da natureza humana está inscrito, em suas linhas mais gerais, em uma ciência que Hume denominou lógica, a qual expôs de maneira breve mas explícita nas "Introduções" do Tratado, da Investigação e do Abstract ${ }^{5}$. Neste último texto, sublinhando cada palavra, Hume assim a descreve: "O fim único da lógica é explicar os princípios e operações de nossa faculdade de raciocinar, e a natureza de nossas ideias [...]" (Hume, 1992, p. 646). Por "natureza de nossas ideias" Hume refere-se aos elementos básicos da constituição de todo o seu

ela progride" (1994, p. viii). Bem mais à frente, a autora nos diz: "Há três tipos de associação em que Hume está interessado no Tratado - em ordem inversa de tratamento -, a saber, associações de pessoas, associações de paixões ou impressões de reflexão, associações de ideias. Eu sugeri que a última deveria ser entendida à luz das afirmações de Hume sobre as outras duas" (1994, p. 52). Percebemos, pela crítica inicial e pela tese defendida, que a dificuldade principal está, para os participantes do debate, em como definir o empirismo, e esta questão é idêntica a de como delimitar a experiência. A estratégia engenhosa de A. Baier desloca a questão epistemológica para o Livro III do Tratado, "Sobre a moral", a partir do qual devem ser lidos os Livros I e II, a saber, "Sobre o entendimento" e "Sobre as paixões". Se adotarmos essa estratégia, perdemos o que H. Allison (2008, p. 13-37) retrata como uma teoria dos elementos, ou seja, somos forçados a abrir mão do método de análise e síntese. Isso significa que, ao invés de tomarmos os elementos, suas inter-relações e possíveis efeitos, passamos a operar aleatoriamente com conjuntos de efeitos característicos, cujo acúmulo moldaria a feição da natureza humana. Isso fica claro, no modo de exposição de A. Baier, pelas citações descontínuas e exaustivas do Tratado, que nos reportam às faces da natureza humana que Hume foi salientando nos inúmeros assuntos alinhavados pelos percursos dessa obra. Tomemos um comentário, à guisa de exemplo, em que a autora se reporta ao problema da memória: "Pessoas em meio a pessoas são os mais vívidos objetos de nossa atenção mental, em parte porque, de muitas maneiras, nós contamos com aquelas pessoas. As associações e relações entre pessoas dão-nos, de modo paralelo, as mais vívidas de todas as nossas concepções de relações" (A. BAIER, 1994, p. 47). Afirmações como essas podem ser extremamente engenhosas e sedutoras, ao acentuar o contrapeso das paixões e laços de natureza humana na composição do que Hume designa por relações. Mas essa leitura jamais poderia nos conduzir a uma inversão da leitura do Tratado, de tal modo que os fundamentos epistemológicos da filosofia experimental decorressem de fundamentos psicológicos. Como bem aponta Deleuze (2001, p. 38-39, 60-63), a ampliação enviesada das paixões - ou seja, a extensão da simpatia calculando perdas logo à vista e ganhos de longo alcance -, a qual estabelece os vínculos mais estáveis e firmes de nossas relações interpessoais, é uma decorrência de configurações epistemológicas que prefiguram modelos de relações sociais. Portanto, sem uma definição inicial dos elementos e das regras do jogo, que estabelecem a base epistemológica da progressiva interpretação, julgamos que um livro como o Tratado perderia muito da pretensão científica que lhe tributava seu autor.

${ }^{5} \mathrm{O}$ fato de ela ser nomeada nestes três textos, distanciados inclusive no tempo, indica que não se trata de um projeto apenas ocasional, mas intencional. $\mathrm{O}$ nome lógica, no entanto, não recobre minimamente as notas características que lhe eram atribuídas pela tradição. Em acordo com esta, Hume lhe atribui o papel de propedêutica, na medida em que de seus fundamentos dependerá a constituição das outras ciências. Contudo, em total incongruência com uma definição sedimentada laboriosa e milenarmente, Hume não a considera como uma ciência da correção do discursivo, mas como ciência dos elementos e operações básicas que assegurarão a constituição da ciência da natureza humana. 
sistema: ideias e impressões ${ }^{6}$. Com "os princípios e operações", designa o segundo passo da ciência da lógica, na qual descreve basicamente duas "faculdades": memória e imaginação.

O primeiro passo, em que obtemos a caracterização das ideias e impressões, é levado a cabo por um procedimento exitoso, ao menos na consideração da maior parte dos comentadores. $\mathrm{O}$ segundo passo, que deve exibir a constituição das "faculdades", ou seja, da memória e da imaginação, guarda uma dificuldade muito maior, pois deve, ao mesmo tempo, apresentar a gênese empírica da subjetividade ${ }^{7}$. Esse segundo passo é levado a cabo em quatro passagens capitais do Tratado (Hume, 1992, p. 9-10, 10-13, 84-86, 627-628 ${ }^{8}$ ), nas quais Hume intenta caracterizar o modo de operar da memória e da imaginação e procura indicar um critério seguro para distinguirmos claramente uma da outra.

Examinemos então o primeiro texto (Hume, 1992, p. 9-10), em que Hume, retomando o fio condutor da lógica, ao mesmo passo caracteriza a natureza de nossas percepções e as relações que estabelecem entre si, conformando assim certos modos de operar. Hume comenta inicialmente:

Nós descobrimos por experiência (by experience), que quando uma impressão foi apresentada à mente, ela faz novamente (again) sua aparição (its appearance) aí (there) como uma ideia; e ela pode fazê-lo depois de dois modos diferentes: ou quando em sua nova aparição ela retém um consi-

\footnotetext{
${ }^{6}$ Por não ocuparem o foco do presente estudo, pressuporemos que podem ser aqui não apresentadas.

${ }^{7}$ Martin Bell, por exemplo, em um texto inteiramente dedicado à leitura de Deleuze sobre Hume, apresentada em Empirismo e subjetividade, de 1953, faz o seguinte apontamento, bastante sugestivo e problemático: "a mente torna-se natureza humana quando ela encontra os princípios da natureza humana refletidos em si própria. Em consequência, Hume cuidadosamente distingue entre ideias que surgem de impressões de sensação, as quais nós podemos considerar como efeitos da matéria e seus princípios, e ideias que surgem de impressões de reflexão, os efeitos da natureza humana e seus princípios" (M. BELL, 2007, p. 102). Ora, o apontamento é sugestivo, porque Hume de fato se recusa a pensar o empirismo como um mero espelhamento mental do dado empírico. Mas é igualmente problemático, porque o segundo passo, a aquisição de uma subjetividade a partir de princípios empíricos, só pode ser alcançada a partir do primeiro, ou seja, a partir da aquisição do suporte da relação - o próprio dado empírico -, extraído de algum modo da experiência e observação. É este entrepasso que o presente texto pretende, senão explicitar detalhadamente, ao menos demarcar como objeto de investigação.

${ }^{8}$ A última passagem encontra-se no "Apêndice" posposto ao Tratado, e nela há menção expressa de Hume para que seja inserida junto com a segunda passagem, na p. 85, linha 22 .
} 
derável grau de sua vivacidade primeira; ou quando ela perde inteiramente aquela vivacidade e torna-se uma perfeita ideia (Hume, 1992, p. 8).

O compromisso assumido na "Introdução" do Abstract (Hume, 1992, p. 646), de extrair conclusões somente na medida em que for autorizado pela experiência, recebe aqui sua confirmação. A descoberta dos elementos básicos da ciência da natureza humana é feita a partir da experiência. Por pressuposto metodológico, aqui é interdito procurar a origem das ideias nas faculdades, como o faz Descartes. Na Terceira Meditação, ao discutir o grau e o modo de representação de cada ideia, Descartes posiciona-as em suas respectivas faculdades, na medida em que correspondem a "poderes" previamente inscritos na subjetividade humana. É assim que as ideias adventícias correspondem aos sentidos, as fictícias à memória e à imaginação, e as inatas ao entendimento 9 . Aqui, uma representação guarda um grau de similitude - para usarmos uma linguagem cartesiana - que nela se inscreve a partir da faculdade na qual ela se instala. Hume recusa este procedimento, e para tratar da memória e da imaginação, refaz o percurso de apresentação das percepções à mente. Se assim procede, é porque o ângulo de estudo deste problema tem de se formar de maneira precisa: tem de abranger memória e imaginação, mas tem também de adotar um ponto de partida que principie com a experiência e observação.

Partindo deste vértice, Hume oferece nesse texto uma fecunda definição empirista do termo ideia - o que não tem sido retido pelo enfoque do comentário especializado. Hume aqui retoma a concepção de ideia como cópia ${ }^{10}$, menos intensa e menos viva em relação à impressão. No entanto, não instala as ideias nas respectivas faculdades, mas no conjunto das percepções, definindo-as como cópias ("appearance") que ocorrem outra vez ("again") e no mesmo lugar ("there"), ou seja, na mente (Hume, 1992, p. 8). Este passo é importantíssimo e precisa ser frisado: Hume não instala as ideias nas faculdades, porque elas não podem ser pressupostas ou estar dadas previamente. Situando as ideias no conjunto das percepções, Hume mantém-se coerente com o pressuposto da filosofia experimental, porque

\footnotetext{
${ }^{9} \mathrm{Na}$ Terceira Meditação, Descartes afirma: "Mas, entre essas ideias, algumas me parecem inatas, outras, adventícias, outras, inventadas por mim mesmo. Pois que eu entenda o que é coisa, verdade, pensamento, não parece que eu o tenha obtido de alhures senão de minha própria natureza. Mas, agora, que ouça um ruído, veja o sol, sinta o fogo, julguei até agora que isso procedesse de certas coisas postas fora de mim. Finalmente, sereias, hipogrifos e congêneres são de minha invenção" (AT, VII, p. 37-38 - FC, III Med., \$10 - ambas as edições, Adam \& Tannery e Fausto Castilho, se encontram na bibliografia). Descartes estabelece uma correspondência direta entre a classificação das ideias e suas respectivas faculdades, sem jamais examinar o porquê determinada faculdade deve ser o locus adequado para receber determinada ideia. Há em Descartes um pressuposto tácito de que as faculdades possuem uma aptidão prévia para colher as ideias que nelas se instalam.

${ }^{10}$ É por esse procedimento que principia a apresentação de sua filosofia seja no Tratado, seja no Abstract, seja na Investigação.
} 
não concebe memória e imaginação como loci já definidos ontologicamente, cujos modos de operar seriam mera consequência dos "poderes" já inscritos em si próprias. Ao contrário, se esses "poderes" manifestam a atuação de forças, são essas forças justamente que têm de poder ser explicadas como resultado de conteúdos aferíveis empiricamente. Contudo, circunscrevendoos no interior das percepções da mente humana, Hume não perde o controle sobre esses conteúdos. As ideias, por conseguinte, não remetem a objetos externos à percepção humana, porque, nesse caso, teríamos dois mundos: o mundo das percepções e o mundo dos objetos externos à percepção. Franqueado esse passo, só um vínculo metafísico poderia restabelecer o contato entre esses dois mundos assim cindidos. Para evitar esse percalço, Hume opera a remissão no interior do conjunto de nossas percepções, pois a todas elas temos acesso por experiência e observação. As ideias, por conseguinte, jamais rompem com o elo da percepção. Logo, elas simplesmente designam as impressões, percepções mais fortes, das quais são cópias ("appearance"), percepções mais fracas, que se apresentam novamente ("again") e posteriormente no mesmo lugar ("there").

Conseguimos assim uma rigorosa definição empirista do termo ideia. Contudo, o objeto deste estudo continua intocado, e precisamos agora retornar a ele: como se constituem então as "faculdades"?

Hume principia a constituição da memória e da imaginação a partir da observação de um traço contraído pelas ideias no interior do conjunto das minhas percepções. Elas podem apresentar-se à mente de dois modos: ou situando-se numa região próxima das impressões, conservando, portanto, um grau maior de força e vivacidade; ou situando-se em uma região distante das impressões, encontrando-se assim destituídas de quase toda a sua força e intensidade. Embora pareça ser precipitado fazê-lo após tão breve definição, Hume conclui: "a faculdade, pela qual repetimos nossas impressões do primeiro modo, é nomeada memória, e a outra, imaginação" (Hume, 1992, p. 8-9). Em virtude da simplicidade dessa passagem, tem ficado obliterado nos comentários a recusa cuidadosa de Hume em se apoiar na memória e na imaginação como se fossem "faculdades"11. Para desconstruir essa iden-

\footnotetext{
${ }^{11}$ Embora essa recusa seja constatável nos escritos humianos, é forçoso considerar que esses mesmos escritos também fornecem percurso para outras hipóteses. G. Strawson comenta: "Pode-se argumentar, no entanto, que há uma confusa ambiguidade no uso que Hume faz da palavra 'mente' ('mind'), que pode explicar porque ele tem sido mal compreendido. Pois, por um lado, ele usa 'mente' para significar, aproximadamente, (1) fenômenos mentais conscientes considerados justamente como tais, [ou seja,] justamente como conteúdos mentais. Enquanto, por outro lado, ele usa esse termo para significar
} 
tificação, Hume evita concebê-las seja como compartimentos nitidamente separados e incomunicáveis, seja como modos de operação já inscritos no sujeito e prévios à aquisição de qualquer conteúdo. Por isso, a primeira descrição que Hume nos dá desse problema não se refere às "faculdades", mas à posição das ideias no interior de nossas percepções: as que estão mais próximas das impressões e que retêm, portanto, maior força e vivacidade, e as que, por estarem mais distantes delas, perdem quase inteiramente essa força e vivacidade, tornando-se - nas palavras de Hume - perfeitas ideias. É a partir dessa descrição que Hume traça a jurisdição das distintas operações da mente. Mas estas operações não são prévias aos conteúdos com que trabalham, mas constituem-se a partir das relações que esses conteúdos estabelecem entre si. Desse modo, a relação mais intensa, entre ideia e impressão, dá origem a um modo de operar que denominamos memória; e a relação menos intensa, entre ideia e ideia, dá origem a um modo de operar que denominamos imaginação. Memória e imaginação, portanto, não designam compartimentos que manifestam uma aptidão prévia para operar com conteúdos, mas referem-se a regiões no âmbito das percepções da mente, em que os conteúdos, ao se inter-relacionarem, originam operações que produzem os atos de lembrar e imaginar.

Ora, notemos que todo esse mundo mental emerge coerentemente, passo a passo, do compromisso que Hume estabelece com o leitor de dar seqüência, em suas construções cognitivas, a uma filosofia experimental. E seu ponto de partida baseia-se em uma asserção bastante simples, que pode ser constatada por experiência e observação, a saber, que "[...] há uma diferença sensível (sensible difference) entre uma e outra espécie de ideias" (Hume, 1992, p. 9). Mas sejamos cuidadosos, Hume não afirma que há uma diferença de natureza ${ }^{12}$ entre as ideias da memória e da imaginação, mas que há

(2) a mente considerada como um todo, em todos os aspectos ontológicos, e, por conseguinte, considerada como algo que pode bem ter (certamente tem de ter) alguma natureza ôntica (some ontic nature) além das percepções ou fenômenos mentais conscientes, alguma dada 'essência ... desconhecida', que é apropriada, por exemplo, para falar dela como contendo ou envolvendo faculdades do sentido, razão e imaginação, e assim por diante" (G. STRAWSON, 1996, p. 131). Esse apontamento é fecundo, porque, para perceber a dificuldade hermenêutica na qual se movem os estudiosos, é preciso aceitar o fato de que o texto de Hume oferece base para duas hipóteses de leitura, as quais podem ser percorridas por distintas perspectivas de investigação. Portanto, não se trata apenas de examinar o que Hume de fato afirmou, como se isso fosse um objeto constatável, mas de testar hipóteses heurísticas de leitura. Por outro lado, para trazer alguma contribuição, é forçoso assumir uma posição em face do debate. O presente texto explora propositalmente a primeira possibilidade heurística apresentada por G. Strawson. 12 M. Malherbe afirma que "quando Hume diz que a ideia representa a impressão, ele não quer dizer nada além. Não é a coisa que é duplicada, mas o seu parecer" (Malherbe, 1992, p. 83). Ou seja, a ideia não representa um objeto posicionado no mundo externo, ela não opera como um signo que remete a uma coisa que se encontra fora do sujeito. Seja o que for esse suposto referente externo, apenas podemos nos certificar de que ele aparece à mente, primeiro, como impressão e, na sequência, como ideia. M. Malherbe 
somente uma diferença de graus de força ou intensidade. Desse modo, não se trata de duas ideias, mas de uma única ideia, cópia de uma impressão singular, que pode se apresentar à mente ora de modo mais intenso, na memória, ora de modo menos intenso, na imaginação.

Hume, neste texto que ora examinamos (Hume, 1992, p. 8-10), opera com dois critérios: o da intensidade e o da ordem, sendo o segundo uma consequência do primeiro. Vimos como Hume parte do primeiro critério, da intensidade, por intermédio do qual faz emergir passo a passo as jurisdições da memória e da imaginação. Para concluir este percurso, falta-nos examinar o segundo critério, da ordem, por meio do qual Hume caracteriza distintamente os modos de operar da memória e da imaginação.

A ordem aqui decorre sensivelmente da intensidade, porque não se trata de uma ordenação racional, mas simplesmente da ordem que procede da sequência das impressões em seu primeiro aparecimento à mente. Porque opera com ideias mais intensas, que se situam mais próximas das impressões, a memória, em suas operações, mantém-se presa a esta ordem e tem de se limitar a reproduzi-la. Hume observa, inclusive, que quando nos desprendemos desta ordem em que as impressões originalmente se apresentam à mente, "[...] produz-se o efeito de uma falha ou imperfeição nesta faculdade" (Hume, 1992, p. 9) ${ }^{13}$.

nos adverte desse fato: a ideia é a duplicação de um primeiro aparecimento, que se constitui pela impressão. Não há uma separação ontológica, mas uma mera gradação de intensidade. Portanto, não há nenhum corte ontológico entre ideias e impressões. Consequentemente, as ideias com que operam a memória e a imaginação se distinguem igualmente somente pela força e vivacidade que manifestam em seu modo de operar.

${ }_{13}$ Kemp-Smith vale-se do critério da ordem para distinguir a memória da imaginação, ao qual associa a oposição entre atividade e passividade. Desse modo, afirma que "[...] na memória a ordem das ideias, tal como a ordem das impressões dos sentidos, é determinada para a mente e não por ela" (Kemp-Smith, 1941, p. 233). A observação de Kemp-Smith torna-se muito fecunda, porque ele consegue mostrar a máxima implicação entre dois princípios de que se vale Hume para constituir empiricamente o modo de operar da memória e da imaginação: o princípio de maior e menor intensidade, de um lado, e o princípio de atividade e passividade, de outro. A maior intensidade da memória, desse modo, tolhe à mente o ato de operar livremente, compondo e decompondo ideias. Por sua própria intensidade, as ideias assumem, no campo da memória, uma ordenação similar à estabelecida no eixo das impressões. O grau de intensidade, portanto, gera um princípio de remissão, o qual estabelece uma forma de ordenação que é dada para a mente. A dificuldade maior, por conseguinte, está em explicar o que denominamos imaginação, pois ela se constitui por um modo de operar que é determinado de algum modo pela própria mente. Recaímos assim no tema deleuziano desse trabalho: se dermos a esse "pela mente" o significado de "por uma faculdade", afirmamos que esse modo de operar é prévio aos conteúdos com que opera; se considerarmos que o fato de haver um modo prévio de operar contradiz os princípios do empirismo, conforme propostos por Hume, então temos de explicar como esse modo de operar surge dos próprios conteúdos, ideias e impressões, adquiridos experimentalmente. 
Também a possibilidade de reordenar decorre da intensidade, mas em sentido inverso. Na medida em que as ideias da imaginação perdem quase por completo sua vivacidade, elas se desprendem da ordem e posição em que as impressões se apresentaram à mente. É isto que assegura à imaginação a possibilidade de operar livremente, permitindo-lhe "[...] transpor e permutar suas ideias" (Hume, 1992, p. 10). Assim, a partir desses dois critérios, da intensidade e da ordem, Hume nos oferece uma clara descrição do modo de operar da memória e da imaginação. Por operar numa região mais próxima das impressões, a memória trabalha com ideias mais vivas, é passiva, não possui liberdade, mantém a ordem e posição das impressões, e sempre singulariza cada ideia remetendo-a ao momento de sua aquisição. Já a imaginação, por operar no polo oposto da intensidade, trabalha com ideias que perderam quase inteiramente sua vivacidade, por conseguinte, é ativa, possui quase irrestrita liberdade, alterando a ordem e posição das ideias por meio das ações de composição e decomposição, e, por fim, para poder executar essas operações, a imaginação precisa evitar o grau de intensidade que a obriga a reportar-se ao eixo das impressões, ou seja, ela precisa desvincular as ideias com que opera do momento de sua aquisição.

O mecanismo da memória, portanto, é inteiramente explicável pelo critério da intensidade e da ordem daí decorrente: lembrar é basicamente recuperar a ordem e posição das impressões em sua primeira aparição à mente. Contudo, se está bem descrito o modo de operar da imaginação, ainda não está claro o mecanismo que lhe permite operar compondo ou decompondo ideias. Por conseguinte, ainda é preciso dar mais um passo no interior do sistema, para que o caráter livre e ativo da imaginação não remanesça como um traço prévio de uma "faculdade" ou como um pressuposto que permanece fora da jurisdição do método experimental.

Sem esquivar-se dela, Hume defronta-se aqui com uma nova dificuldade: a memória, em virtude do princípio de intensidade, pode ser explicada analogicamente em relação ao eixo das impressões; a imaginação, entretanto, por estar distante e quase desprendida deste eixo, parece ocultar-nos seus princípios, porque não podemos pressupor um princípio de organização dado previamente, nem podemos reivindicar um princípio de organização externo a si própria, na medida em que não há base experimental visível para que possamos lançar mão deste procedimento. Ou seja, a dificuldade está em explicar o eixo da intensidade em seu polo oposto, isto é, na região do menos intenso. Nessa região, a relação das ideias produz conexões que, por não poderem ser explicadas somente a partir do eixo ideia-impressão 
(pelo princípio da intensidade), têm de ser explicadas a partir do eixo ideiaideia (pelo princípio compositivo).

Hume enfrenta esta dificuldade na Seção IV do Tratado (Livro I, Parte I), onde se ocupa "da conexão ou da associação de idéias". Para examinar esta questão, principia por uma dupla constatação. De um lado, frisa a extrema liberdade da imaginação para separar as ideias e uni-las da forma que mais lhe agradar. De outro lado, argumenta que "se as ideias fossem inteiramente soltas e desconexas, somente o acaso as juntaria" [...] (Hume, 1992, p.10). No entanto, recusa esta hipótese pela constatação de que há um padrão de regularidade nos procedimentos compositivos da imaginação. Ora, se este padrão de regularidade existe, de que modo é ele produzido? - esta é a principal questão de Hume. Esta questão admite duas respostas. A primeira é simples e direta. Hume afirma que a imaginação é guiada por alguns princípios universais, os quais a tornam "[...] uniforme consigo própria em todas as épocas e lugares" (Hume, 1992, p. 10). Vejamos, Hume diz que ela torna-se uniforme não com alguma coisa, mas consigo própria. Ou seja, se seu modo de operar assume um padrão, esse não pode ser atribuído nem a um parâmetro externo, pois pressuporia uma regularidade inscrita nas coisas, nem a uma aptidão prévia, que potencialmente estaria inscrita nesta "faculdade". Logo, esse padrão, se houver, terá que se formar no exercício da própria "faculdade", de tal maneira que o modo de operar da imaginação possa ser explicado a partir dos elementos encontrados por experiência e observação, que são, neste estágio de investigação, ideias e impressões. Mas já abrimos mão das ideias mais vívidas, que remetem ao momento de sua aquisição na sequência das impressões, porque elas caracterizam o modo de operar da memória. Desse modo, se há princípios que tornam a imaginação uniforme consigo própria, eles têm de ser extraídos das relações que as próprias ideias estabelecem entre si.

Mas como extraí-los? Aqui principia a segunda resposta, que nos conduz ao fundamento dessas relações. Hume afirma que este princípio de união entre as ideias deve ser considerado "[...] como uma força branda que comumente predomina [...]" (Hume, 1992, p. 10). E que é produzido mediante "[...] alguma qualidade associativa, pela qual uma ideia introduz naturalmente outra" (Hume, 1992, p.10). É por meio dessa qualidade, afirma Hume, que "[...] a mente é conduzida dessa maneira de uma ideia a outra [...]" (Hume, 1992, p. 11). Notemos, mais uma vez, como, para avançar no percurso da investigação, Hume é forçado a retornar a elementos que estão na base do método experimental, neste caso, às ideias, sendo obrigado a redefini-las. Assim, saímos aqui momentaneamente do eixo da intensidade e ingressamos no domínio das qualidades. As ideias, por experiência e observação, são então definidas como um conjunto de qualidades formadas a partir das percepções. A ideia de maçã, por exemplo, é um conjunto de outras ideias simples - relativas à cor, tamanho, forma, textura, sabor, etc. - formadas no fluxo da percepção. As ideias, portanto, são um conjunto de 
qualidades que dão origem a um conjunto de relações. Nesse sentido, as relações não estão inscritas na mente nem nos supostos objetos externos, nem são propriedades prévias das faculdades. As relações são simplesmente consequências naturais das qualidades que são imanentes às ideias. Esta característica é muito importante, por isso é preciso sublinhá-la: Hume afirma que "[...] naturalmente uma ideia introduz outra [...]" (Hume, 1992, p. 10). Assim, a mente associa naturalmente suas ideias por meio de qualidades que, ao introduzir relações, produzem também o domínio do componível e do separável, que designamos como imaginação. Isto nos permite entender um pressuposto central do Tratado, sobre o qual se constroem muitos dos argumentos de Hume, e que se refere à capacidade da imaginação de associar o simples e decompor o complexo ${ }^{14}$. Esse pressuposto pode ser reformulado da seguinte maneira: o domínio do componível naturalmente é congruente com o domínio do separável naturalmente. Ou seja, tudo o que está no limite da percepção pode ser composto ou decomposto no domínio das ideias, sem que haja qualquer vínculo ontológico seja na estrutura da realidade seja na estrutura da imaginação que impossibilite essas operações da mente humana ${ }^{15}$. Esta força compositiva ou decompositiva, portanto, não emerge nem de relações previamente inscritas na realidade nem de uma capacidade obscuramente inscrita na imaginação, mas é simples decorrência, aferível por experiência e observação, das qualidades imanentes às próprias ideias. É mediante estas qualidades que a mente é conduzida de uma ideia à outra na imaginação, movimentando-se com certa regularidade que Hume procurava descrever a partir de alguns princípios. Estes princípios, na visão do autor e também dos comentadores ${ }^{16}$, encerram uma grande contribuição para a anatomia da mente humana, na medida em

${ }^{14}$ P. J. Smith ressalta a frequência com que "[...] Hume invoca a tese de que onde quer que a investigação perceba uma diferença, ela pode separar as duas ideias (T. 10, 18, 24, 27, 32, 38, 40, 54, 79, 87, 95- 96, etc.)" (1995, p. 59).

${ }^{15}$ A importância desse princípio também é destacada por C. A. R. de Moura: "Que 'tudo o que é diferente é separável' é uma tese filosófica que Hume introduz explicitamente no Tratado e implicitamente na Investigação, fazendo-a desempenhar um papel decisivo não só na destituição da noção moderna de razão, com a consequente promoção da 'experiência' a única fonte possível do conhecimento dos 'fatos', como também na constituição da maior parte de suas 'doutrinas'. [...]. Ela estará subjacente também à recusa dos conceitos ontológicos da tradição, à crítica da ideia de existência, à recusa das ideias abstratas e à dissolução da noção de 'eu', sem que esta listagem seja de forma alguma exaustiva" (1997, p. 159-160). Pelo comentário de C. A. R. de Moura podemos perceber a abrangência desse princípio, cuja importância se manifesta não somente por sua incidência quantitativa, mas também pelo fato de que ele qualifica muitos dos argumentos que formam a base da peculiar formulação do empirismo de David Hume. ${ }_{16}$ A fecundidade dos princípios de associação e a importância que Hume se atribui por tê-los descoberto é um ponto em comum destacado pelos comentadores (P.J. Smith, 1995, p. 58-60; J. Biro, 1998, p. 35-36; S. R. Romeo, 2004, p. 324-326; Y. Michaud, 1999, 115-117). Embora coloque em discussão a influência do método de Newton sobre os procedimentos adotados por Hume, Y. Michaud, comentando o problema de associação, afirma que "os termos nos quais Hume apresenta sua 'descoberta' manifestam seu desvelo de ser o Newton do espírito humano" (1999, p. 115). 
que permitem equacionar todas as operações da imaginação, reduzindo-as a três relações básicas: semelhança, contiguidade no tempo e no espaço, e causa e efeito.

Aqui começamos a superar a dificuldade anunciada acima. Ela dizia respeito a como explicar o fato de a imaginação operar livremente sem atribuirlhe características previamente nela inscritas. Vimos que se isto não fosse resolvido, geraríamos lacunas na aplicação do método experimental, uma vez que teríamos de pressupor componentes do sistema que não poderiam ter sido obtidos por experiência e observação.

Façamos agora uma sinopse da solução alcançada. A imaginação, conforme o que foi exposto, não contém relações que precedem ao aparecimento dos conteúdos com que opera, pois nesse caso ela deveria possuir relações prévias aos termos dados, às quais estes termos se submeteriam. As próprias ideias é que produzem relações entre si, e ao efeito dessa inter-relação é que se denomina imaginação. A imaginação não designa, portanto, uma faculdade previamente dada, mas o modo de operar da mente, que ocorre quando, ao invés das ideias serem ordenadas por sua remissão à impressão, elas são associadas a partir das relações que estabelecem entre $\mathbf{s i}^{17}$. Assim, uma ideia, através de uma qualidade, conduz o pensamento a outra ideia, por meio de um nexo que tem de ser obtido empiricamente.

Se o princípio de intensidade é insuficiente para explicar a imaginação, é porque, quando imaginamos, as ideias não são remetidas às impressões (ou a suas posições datadas - o que é recurso da memória), mas são, por meio de suas próprias qualidades, remetidas a outras ideias. Após serem adquiridas, as percepções menos intensas passam a se relacionar entre si, ultrapassando, nessa inter-relação, os dados pontuais das impressões que lhes

\footnotetext{
17 A questão sobre quais forças compõem a mente humana está sempre em jogo nos comentários e exegeses, e é fundamental para se delimitar o modo como pode ser compreendida a obra de David Hume. Para exemplificarmos isso, vejamos o seguinte comentário, firme e claro, de A. E. Pitson: "razão (reason) é uma faculdade de inferência, que implica ou uma comparação das próprias ideias (raciocínio demonstrativo), ou uma inferência de uma impressão dos sentidos - ou de uma que está retida na memória a uma ideia (raciocínio provável). Há uma conexão entre imaginação e razão, que consiste no fato de que as ideias às quais o raciocínio dá origem são elas próprias ideias da imaginação (isto é, como opostas às ideias da memória, que simplesmente repetem as impressões)" (A. E. PITSON, 2002, p. 146). Este seguro comentário resolve de maneira simples muitas passagens não tão claras de David Hume, pressupondo que o raciocínio demonstrativo e o raciocínio causal são operações da razão, executadas a partir de ideias e relações inscritas na imaginação. Ou seja, para fazer este claro comentário, A. E. Pitson aceita o pressuposto de que há duas faculdades (razão e imaginação) em oposição a uma terceira (memória); as duas primeiras estão conectadas pelo fato de operarem com o mesmo tipo de ideias (menos intensas), distintas das ideias com que opera a memória (mais intensas). A grande questão, independentemente do fato de Hume empregar o termo razão e atribuir-lhe ou não um sentido distinto, é se há base experimental no interior da teoria para se pressupor a existência dessa faculdade.
} 
deram origem. Muito da crítica de Hume à Metafísica resulta da constatação de que essa inter-relação pode produzir uma hipóstase, a partir da qual julgamos que as relações estão inscritas nas próprias coisas, sem nos atermos ao fato de que são efeito de qualidades separáveis que conectam ideias na imaginação. São essas qualidades, características empíricas das ideias, que produzem os princípios de inter-relação que denominamos imaginação, a saber: semelhança, contiguidade no tempo e no espaço, e causa e efeito. São estes princípios ou relações naturais que detêm a branda força ordenadora da imaginação, e que impedem que ela se mova caoticamente e imponderadamente para qualquer direção.

Recorramos, por fim, ao texto da Seção V (Livro I, Parte III) do Tratado (Hume, 1992, p. 84-86) e aos argumentos do respectivo "Apêndice" (Hume, 1992, p. 627-628), para entendermos a radicalidade da concepção humiana. Nos dois textos anteriores, acima analisados, Hume procurava caracterizar o modo de operar da memória e da imaginação, e numa analogia com o procedimento newtoniano, intentava reduzir as diversas manifestações dos fenômenos observados a alguns princípios que pudessem fornecer uma chave de sua explicação. Assim, segundo os modos de operar, a memória atuava com ideias mais vivas e próximas das impressões, e na sequência de suas ideias procurava recuperar a ordem e a posição que reproduzisse o momento da aquisição de suas respectivas impressões. A imaginação, por sua vez, trabalhava com ideias menos vivas e mais distantes das impressões, e parecia ter liberdade quase irrestrita para compor e decompor ideias. Em relação aos princípios, a memória atinha-se ao vínculo estabelecido entre ideia e a sua respectiva impressão. Já a imaginação era impelida por uma força branda, que regulava suas operações segundo as relações de semelhança, contiguidade e causa e efeito.

Do ponto de vista metodológico, a passagem ora analisada representa uma tentativa ainda mais radical do propósito científico de Hume, porque ele intenta reduzir os modos de operar e os princípios que os produzem a um único fundamento. Para alcançar esse feito, Hume inicialmente parece até desconstruir as análises que tinha levado a cabo anteriormente, na medida em que relativiza os critérios que são pertinentes, mas não decisivos, para o objetivo em curso. Se assim procede, é porque aqui não se trata de opor memória e imaginação a partir de seus respectivos modos de operar, mas de encontrar o traço distintivo que possibilite separar as ideias da memória das ideias da imaginação.

Para levar a termo essa tarefa, Hume inicialmente quase torna indistintas memória e imaginação, pois principia pela análise dos critérios que não as 
diferenciam. Em primeiro lugar, recorre ao argumento da fonte, afirmando que a memória e a imaginação não se distinguem pelas ideias simples com que operam, uma vez que "[...] ambas as faculdades emprestam suas ideias simples das impressões [...]" (Hume, 1992, p. 85). Nesse sentido, a memória e a imaginação não se distinguem por receberem ideias distintas em seus recintos - pelo contrário, do ponto de vista da natureza das ideias, elas operam, pode-se dizer, no mesmo plano ontológico -, mas se caracterizam como conjuntos de operações, cuja única fonte são as impressões. Em segundo lugar, Hume salienta que não é somente a partir das ideias simples que a memória e a imaginação não podem ser distinguidas, mas também em relação à disposição de suas ideias complexas. Consoante este argumento, nem mesmo o critério da ordem seria suficiente para distingui-las. Se a imaginação é livre ao operar, ela pode bem simular as ações da memória e construir uma sequência de ideias semelhante à que seria reproduzida pela memória em suas operações. E não há como se certificar da correção dessas operações, pois, observa Hume, é "[...] impossível reevocar as impressões passadas, a fim de compará-las com nossas ideias presentes e ver se sua disposição é exatamente similar" (Hume, 1992, p. 85).

Mas se esses dois argumentos relativizam as distinções anteriormente construídas, é justamente para pôr em relevo o critério principal, a partir do qual se explicitará o sentido de todos os outros. Hume conclui: "portanto, já que a memória não é conhecida nem pela ordem de suas ideias complexas, nem pela natureza de suas ideias simples; segue-se que a diferença entre ela e a imaginação repousa em sua superior força e vivacidade" (Hume, 1992, p. 85). Para explicitar o alcance operatório desse princípio, Hume o ilustra, no "Apêndice" do Tratado (1992, p. 627-628), com o exemplo de dois homens entretidos em recordar um episódio vivenciado em mútua companhia, com a peculiaridade de que um se recorda exatamente das vívidas cenas, que já não podem ser localizadas pela memória do outro. Num comportamento antropológico corrente, aquele que se recorda evoca a sequência das cenas e as circunstâncias em que ocorreram. O que um narra inteiramente de memória, o outro acompanha fragmentariamente pela imaginação, sem o domínio do contexto, até que ocorre o que alguns memorialistas designam de "gatilho", ou seja,

[...] assim que é mencionada a circunstância que toca a memória, as mesmas idênticas ideias aparecem então sob uma nova luz, e asseguram, de algum modo, uma sensação (feeling) diferente da que possuíam anteriormente. Sem nenhuma outra alteração, a não ser essa [exercida] na sensação (feeling), elas tornam-se imediatamente ideias da memória, e se lhes concede assentimento (HUME, 1992, p. 628).

O principal mérito dessa passagem é o de mostrar como uma mesma ideia pode migrar da imaginação para a memória e vice-versa, valendo-se, mediante uma redução extrema, apenas do princípio da intensidade. A diferença, portanto, entre memória e imaginação não se dá a partir das propriedades 
inscritas nessas "faculdades", mas a partir do modo de apresentação na mente das próprias ideias, ou seja, a partir do distinto modo de afecção como aí se manifestam. É por meio desse procedimento que um homem, investindo sobre a imaginação de outro, consegue evocar na mente de seu companheiro as cenas mais vívidas que compõem a memória de um episódio. Com isso, Hume assegura que se trata justamente das mesmas ideias, que, ao migrarem para campos distintos de intensidade no interior da mente, contraem propriedades que forçam os conteúdos a interagir, gerando as operações que nomeamos imaginar ou recordar. Fixando mediante inúmeras repetições estas operações, terminamos, por hipóstase, instalando-as no interior de "faculdades", como se essas "faculdades" possuíssem a priori as propriedades a que submetem seus conteúdos. Quando assim procedemos, deixamos de atentar para o fato de que esses conteúdos - em conformidade com os princípios radicais da filosofia experimental de Hume - podem estabelecer entre si as relações que lhes permitem operar segundo essas propriedades, que identificamos nos atos de recordar e imaginar. $\mathrm{Na}$ ausência dessa hipótese, consideramos memória e imaginação como compartimentos estanques, separados, definidos por propriedades que lhes são imanentes. Em decorrência disso, perdemos de vista uma contribuição original de David Hume, que é a de estabelecer a comunicação e a transição entre os modos de operar da memória e da imaginação mediante a utilização do simples princípio da intensidade ${ }^{18}$, a partir do qual podem vir a ser

\footnotetext{
18 A incompreensão desse princípio, principalmente de seu caráter operatório, pode nos afastar do modo como a filosofia experimental de Hume apreende memória e imaginação. David Pears (1996, p. 41), por exemplo, aponta corretamente que o critério de força e vivacidade permitiria separar as ideias da memória das da imaginação. Mas não consegue perceber que o mesmo critério que separa essas ideias também regula os modos de operação do que denominamos "imaginar" e "recordar". Mais do que isso, embora comente várias vezes o exemplo da conversa entre dois homens que viveram um mesmo acontecimento, com a diferença de que um se recorda vividamente das cenas que se passaram e o outro não, D. Pears jamais se reporta ao fato de que o critério de força e vivacidade possibilita que uma mesma ideia possa passar da imaginação para a memória e vice-versa. A ausência dessa chave de transição entre dois modos de operar da mente humana pode ser constatada na engenhosa questão proposta à epistemologia de Hume e que D. Pears designa como "imagens enquanto data". Trata-se de uma hipótese engenhosa, porque ela gera uma assimetria entre os elementos básicos que articulam a reflexão humiana no Livro I do Tratado. Esta hipótese nomeia "imagens enquanto data" aquelas imagens que perpassam a mente sem trazerem consigo nenhuma referência explícita às impressões que lhes deram origem. No entanto, parece bem problemática a afirmação de que a memória possa operar com imagens enquanto simples data, uma vez que ela jamais pode operar fora do âmbito do que D. Pears designa como teoria da referência, ou seja, sem se reportar a uma impressão passada tomada enquanto alvo da significação de uma ideia que se encontra na mente. De modo perspicaz e elucidativo, D. Pears comenta que as impressões não dependem da teoria da referência, uma vez que Hume "[...] trata o conhecimento perceptivo como intuitivo (como se as impressões identificassem a si próprias e falassem por si próprias)" (1996, p. 33); e afirma que as "imagens enquanto data" também dela não dependem. Ora, esse comentário se fixa em uma bem armada assimetria, porque não recobre as estruturas básicas da teoria de Hume, ou seja, dois elementos (impressões e ideias) e duas
} 
decompostas todas as propriedades que atribuímos à memória e à imaginação. Por esse procedimento, essas supostas "faculdades", tomadas incautamente como dadas a priori, podem ser então reconduzidas ao trajeto investigativo de uma filosofia experimental.

Notemos o escopo do argumento: Hume quer reduzir todas as diversas manifestações fenomênicas da memória e da imaginação a um único princípio, isto é, o da intensidade, que pode ser construído por experiência e observação. Este era justamente o requisito do procedimento de análise que poderia caracterizar a filosofia experimental: alcançar princípios explicativos gerais, cuja construção não dependesse de hipóteses que não podem ser aferidas por experiência e observação.

Notamos aqui como Hume é inteiramente consequente com esta exigência, que foi apresentada, no início deste texto, como o compromisso básico que ele estabelecia com o seu leitor. A partir disso, podemos também entender melhor a sequência da argumentação, que evita progredir caso seus passos não possam ser dados em conformidade com o método experimental. Para nos certificarmos disso, de posse do critério da intensidade, reexaminemos a argumentação. Hume afirma que nem o simples nem o complexo, nem a ordem nem a posição nos permitem identificar a faculdade atuante. Qual

operações (memória e imaginação). Ao delimitar os problemas da significação, da inferência e da verdade, D. Pears (1996, p. 31-33) decompõe de modo perspicaz três estruturas: impressões, memória e imagens enquanto data (ou seja, imagens que ocorrem "[...] sem uma função" (1996, p. 35) de remissão ao seu referente). Mas não lhe ocorre perguntar se as imagens enquanto data não podem substituir a função que Hume denomina imaginação. Desse modo, imagens seriam os correspondentes do que Hume denomina impressões; imagens mais vívidas contrairiam as propriedades do que Hume nomeia memória; enquanto imagens menos vívidas formariam o jogo de composição e decomposição ao qual Hume denomina imaginação. Assim, a simetria das estruturas básicas do empirismo de Hume seria reestabelecida. No entanto, vemos D. Pears costear a imaginação sem adentrá-la e caracterizá-la, porque está ausente do comentário a chave simples que permite converter uma ideia da memória em ideia da imaginação, a saber, a intensidade, e que possibilita regular as funções mediante as quais percebemos que estamos relembrando ou imaginando alguma coisa. Mas que fique bem claro: não está ausente do comentário o critério basilar da força e vivacidade; a deficiência, em nosso ponto de vista, está em que jamais é explicitado o modo como esse critério permite articular e executar as operações da memória e da imaginação, criando uma intercomunicação entre elas. Portanto, podemos dizer que tomada enquanto data, uma ideia da memória não "[....] flutua na mente de uma pessoa [...]" (PEARS, 1996, p. 31), porque eliminada a referência a uma impressão passada, a função da memória se dissolve; por outro lado, podemos compreender que uma imagem enquanto data pode flutuar na imaginação, sendo composta e decomposta segundo seus princípios de conexão. 
seria então a diferença entre a memória e a imaginação? Hume as trata como o resultado da somatória de forças que formariam campos de atuação distintos no interior da esfera das nossas percepções. Estas forças, portanto, são geradas pelos próprios conteúdos, impressões e ideias, na medida em que ingressam no conjunto de nossas percepções.

Neste sentido, podemos afirmar que memória e imaginação são consequências naturais do conjunto de percepções a que a mente tem acesso, ou seja, memória e imaginação são propriedades das relações possíveis entre os conteúdos das percepções. É preciso frisar este argumento: Hume não discute as faculdades como "poderes" inscritos na mente, que antecederiam os dados com que operam; ao contrário, as faculdades são consequências das relações de forças estabelecidas entre conteúdos determinados a partir de uma fonte empírica. A ordenação das faculdades, portanto, é consequência da forma de relação entre conteúdos extraídos da experiência. Inversamente - e aqui se impõe um compromisso metodológico -, as faculdades só podem ser fundadamente investigadas a partir de um suporte empírico que ofereça base de observação: as percepções.

As propriedades que caracterizam as operações da memória e da imaginação advêm, portanto, das relações entre ideias e impressões. Pelo fato de estas relações serem mais intensas ou menos intensas é que nós operamos recordando ou imaginando. Ou seja, as relações são produtos dos próprios conteúdos (ideias e impressões) e não das faculdades (memória e imaginação). Neste sentido e em conformidade com a hipótese aqui inicialmente levantada, não há um sujeito prévio - em que as faculdades antecedem o conteúdo a ser por elas captado -, mas há uma subjetividade sempre em constituição, cujas faculdades, inicialmente, são consequência natural dos conteúdos a que se tem acesso, e das relações possíveis de serem contraídas por esses conteúdos.

\section{Bibliografia}

ALLISON, Henry E. Custom and reason in Hume: a Kantian reading of the first book of the Treatise. Oxford: Clarendon, 2008.

BAIER, Annette C. A progress of sentiments: reflections on Hume's Treatise. Cambrigde: Harvard University Press, 1994.

BELL, Martin. Transcendental empiricism? Deleuze's reading of Hume. In: FRASCASPADA, Marina; KAIL, P. J. E. (Org.) Impressions of Hume. Oxford: Clarendon Press, 2007. p. 95-106.

BIRO, J. Hume's new science of the mind. In: NORTON, D. F. The Cambridge companion to Hume. New York: Cambridge University Press, 1993.

DELEUZE, G. Empirismo e subjetividade. Ensaio sobre a natureza humana segundo Hume. Tradução de Luiz B. L. Orlandi. São Paulo: Ed. 34, 2001. 
DESCARTES. Oeuvres de Descartes. Editadas por Charles Adam e Paul Tannery. Paris: Vrin, 1996. v. VII.

Meditações sobre Filosofia Primeira. Edição bilíngüe. Tradução e nota prévia de Fausto Castilho. Campinas/SP: Editora da Unicamp, 2004.

HUME. A treatise of human nature. $2^{\text {nd }}$ ed. by L. A. Selby-Bigge. With text rev. by P. H. Nidditch. Oxford: Claredon Press, 1992.

. Tratado da natureza humana. São Paulo: Edunesp, 2001.

An enquiry concerning human undestanding. Chicago: Encyclopaedia Britannica (Great books of the western world; v. 35), 1952.

Investigação sobre o entendimento humano. Lisboa: Edições 70, 1989.

An Abstract of a book lately published; entitled, A treatise of human nature. In: HUME. A treatise of human nature. $2^{\text {nd }}$ ed. by L. A. Selby-Bigge. With text rev. by P. H. Nidditch. Oxford: Claredon Press, 1992. p. 641-662.

. Abrégé du traité de la nature humaine. Présentation, traduction et notes par Didier Deleule. Ed. bilingue. Paris: Aubier Montaigne, 1971.

KEMP-SMITH, N. The philosophy of David Hume. A critical study of its origins and central doctrines. London: Macmillan, 1941.

MALHERBE, M. La philosophie empiriste de David Hume. $3^{\text {a }}$ ed. Paris: Vrin, 1992.

MICHAUD, Y. Hume et la fin de la philosophie. Paris: Quadrige; PUF, 1999.

MOURA, C. A. R. Crítica humeana da razão. Manuscrito, Campinas/SP, v. XX, n. 2, p. 145-167, out. 1997.

NOXON, J. La evolución de la filosofía de Hume. Tradução de Carlos Sólis. Madrid: Alianza Editorial,1987.

PEARS, David F. Hume's system: an examination of the first book of his Treatise. New York: Oxford University Press, 1996.

PITSON, A. E. Hume's philosophy of the self. London and New York: Routledge, 2002.

ROMEO, S. R. El empirismo: David Hume. Madrid: Trotta; Xunta de Galicia, 2004.

SMITH, P. J. O ceticismo de Hume. São Paulo: Loyola, 1995.

STRAWSON, Galen. The secret connexion. Causation, realism and David Hume. Oxford: Clarendon Press, 1996.

Endereço do Autor:

Rua Eugênia Conceição Oliveira 50

Presidente Roosevelt

38401-143 Uberlândia - MG

mseneda@ufu.br 